\title{
Paraoxonase1 Activity and Paraoxonase1 Q192R Gene Polymorphism in Systemic Lupus Erythematosus Patients as a Risk Factor for Atherosclerosis
}

\author{
Mona I. Nabih ${ }^{1}$, Amal R. El-Shehaby ${ }^{2}$, Hussein Heshmat ${ }^{3}$ \\ Departments of Internal Medicine ${ }^{1}$, Medical Biochemistry ${ }^{2}$, Cardiology ${ }^{3}$, Cairo University; Egypt
}

\begin{abstract}
Background: Accelerated atherosclerosis has become an important cause of death in Systemic Lupus Erythematosus (SLE) patients. The protective role of HDL-C against atherosclerosis is believed to be mainly due to the enzyme paraoxonase 1 (PON1) which functions to prevent LDL-C from peroxidation. Decreased PON1 activity has been observed in SLE patients. Objectives: In the present study, we aimed to determine the PON1 activity and PON1 Q192R polymorphism in SLE patients and to study their relation to premature atherosclerosis. Methods: 40 SLE patients and 20 age \& sex matched controls were included. PON1 activity was determined by paraoxon substrate. PON1 genotyping was conducted by PCR followed by polymorphism-specific restriction enzyme digestion and gel electrophoresis. Atherosclerosis was assessed by intima-media thickness (IMT). Results: Significantly lower PON1 activity and higher IMT was found in SLE patients compared to controls $(\mathrm{p}<0.05)$. Significant negative correlation was observed between PON1 activity and IMT, SLEDAI score, total cholesterol and LDL-C. There was no significant difference in the prevalence of any of the PON1 Q192R polymorphisms in SLE patients compared to controls. PON1 activity was lowest in the QQ, intermediate in $Q R$ and highest in RR group $(p<0.05)$ and the mean IMT was highest in RR, intermediate in QR and lowest in QQ group $(\mathrm{p}<0.05)$. Conclusion: Although there was no association between any of the PON1Q192R polymorphism and SLE, PON1 activity was significantly decreased in SLE patients and was significantly correlated with the severity of atherosclerotic lesions. And thus, it might be involved in the pathogenesis of atherosclerosis in SLE patients. [Egypt J Rheumatology \& Clinical Immunology, 2014; 2(1): 27-35]
\end{abstract}

Key Words: SLE, paraoxonase activity, PON1Q192R polymorphism, atherosclerosis.

\section{INTRODUCTION}

Systemic lupus erythematosus (SLE) is a chronic inflammatory autoimmune disease characterized by systemic inflammation and increased production of a wide range of auto-antibodies directed against a multiplicity of antigens. Accelerated atherosclerosis and early coronary artery disease (CAD) have become important causes of death and hospitalization in SLE patients. The risk of myocardial infarction in SLE patients is 50 times higher than the general population ${ }^{1}$ and coronary artery disease accounts for up to $30 \%$ of all deaths in some reported series ${ }^{2}$.

Classic risk factors for cardiovascular disease in SLE appear to be similar to those in the general population, but specific factors such as steroid treatment, chronic inflammation, and renal disease could account for enhanced atheroma formation ${ }^{3}$. Dyslipoproteinemia is a major factor in the development of atherosclerosis in SLE

Correspondence to Mona I. Nabih, Department of Internal Medicine, Cairo University; Egypt.

e-mail:monainabih@gmail.com patients who are characterized by elevated triglycerides and very low-density lipoprotein cholesterol (VLDL-C) and reduced levels of high-density lipoprotein cholesterol (HDL-C) and apolipoprotein (Apo) A- $1{ }^{4}$

The oxidative modification of low-density lipoprotein cholesterol (LDL-C) in the arterial wall is believed to be the major pathogenetic mechanism behind the initiation and acceleration of atherosclerosis, and thus, coronary artery disease ${ }^{5}$. HDL-C on the other hand is known to have a protective effect. The protective role of HDL-C is believed to be mainly due to the enzyme paraoxonase 1 (PON1), a $\mathrm{Ca}^{++}$dependent esterase, bound to its surface and functions to prevent LDL-C from peroxidation, which is believed to be central to the pathogenesis of atherosclerosis ${ }^{6}$. In addition to preventing peroxidation, it also hydrolyzes the oxidized LDL as shown in-vivo and in-vitro studies ${ }^{7,8}$. It has been shown that PON1 knockout mice cannot hydrolyze the oxidized LDL and have increased risk of developing $\mathrm{CAD}^{9}$. This has led to the hypothesis that the lower the PON1 activity is, the higher will be the accumulation of oxidized LDL and susceptibility to atherosclerotic disease and CAD. 
There is a wide variation in PON1 activity in different ethnic groups and within individuals in the same ethnic group ${ }^{10}$. The human PON1 gene is located on the long arm of chromosome 7 between q21.3 and q22.1 with other members of its supergene family ${ }^{11}$. Two common coding region single nucleotide polymorphisms (SNP) in PON1 gene occur; a glutamine (Q) to arginine (R) substitution at position 192 (Q192R) which affects PON1 enzyme activity and a leucine (L) to methionine (M) substitution at position 55 (L55M). The amino acid polymorphism at position 192 results in two alloenzymes, which differ in their hydrolytic activity towards lipid-peroxides. The A alloenzyme (Glu at 192) is more efficient at hydrolyzing lipid-peroxides on LDL than the B alloenzyme (Arg at 192) which may be relevant to the anti-atherogenic role of PON $1^{12}$. Thus, the PON1 polymorphisms are important in determining the capacity of HDL to protect LDL against oxidative modification and this may explain the relationship between the PON1 alleles and CAD in case-control studies $^{13}$

There is emerging evidence that PON1 activity is decreased in SLE patients, thus interfering with the protective functions of HDL favoring atherogenesis ${ }^{14}$.

We aimed in the present study to determine the PON1 Q192R polymorphism and PON1 activity in SLE patients and to study their relation to premature atherosclerosis assessed by IMT and to some of the other risk factors for cardiovascular diseases in SLE patients.

\section{SUBJECTS AND METHODS}

Subjects

The study comprised a total of 40 SLE women with a mean age of $27.63 \pm 6.11$ years. All patients fulfilled the updated American college of rheumatology revised criteria for the classification of $\mathrm{SLE}^{15}$. Patients were recruited from the Internal Medicine departments and Outpatient Clinics of Cairo University Hospital. Consecutive eligible patients, aged $>18$ years were enrolled. All parameters that are known to influence PON1 activity, such as smoking, diabetes mellitus, chronic renal failure, nephrotic syndrome and lipid lowering drug intake, were excluded. Also, patients with a history of myocardial infarction, angina or stroke were excluded. Twenty age and sex matched healthy volunteers served as controls. An informed consent was obtained from all participants in the study.

\section{Methods}

Patients were subjected to full history taking including current drug therapy, thorough clinical examination including systolic blood pressure (SBP), diastolic blood pressure (DBP) and body mass index (BMI).

Blood specimens were collected from patients and controls after an overnight fast for the assessment of complete blood count (CBC), fasting blood glucose (FBG), serum creatinine, total cholesterol (TC), LDLC, HDL-C, triglycerides (TG) and PON1 activity. Peripheral blood leucocytes isolated from EDTAtreated blood was used for genomic DNA preparation. Samples were stored at $-80^{\circ} \mathrm{C}$ until analysis of PON1 activity and genotypes.

In patients with SLE, erythrocyte sedimentation rate (ESR), antinuclear antibody (ANA), anti-doublestranded DNA and serum complement levels C3 \& C4 were measured. Complete urine analysis for casts and proteinuria by dipstick measurement were also assessed. SLE disease activity was assessed using the SLE disease activity index (SLEDAI) score ${ }^{16}$.

PON1 activity assay: Paraoxonase activity was measured according to Furlong et al. (1988) ${ }^{17}$. Paraoxonase activity was measured using $1.2 \mathrm{mM}$ paraoxon (O, O-diethyl, p-nitrophenyl phosphate) provided by Sigma-Aldrich/ Fluka, St. Louis (USA) as a substrate; in $50 \mathrm{mM}$ Tris $\mathrm{HCl}$ buffer $(\mathrm{pH}$ 6.8) containing $1.0 \mathrm{mM} \mathrm{CaCl}_{2}$. The rate of generation of 4nitrophenol was monitored at $25^{\circ} \mathrm{C}$ with a continuously recording spectrophotometer at $412 \mathrm{~nm}$.

PON activity $=[\Delta \mathrm{Abs} / \mathrm{min}) \times(1 / \varepsilon)(\mathrm{tv} / \mathrm{sv}) \times$ $(1 / \mathrm{d})] \times 109$, where $\Delta \mathrm{Abs} / \mathrm{min}$ is blank-corrected change in absorbance/min, $\varepsilon$ is the molar absorbance coefficient, (7480 liter $\cdot$ mol- $1 \cdot \mathrm{cm}-1)$, tv is the total reaction volume $(0.3 \mathrm{ml})$, $\mathrm{sv}$ is the sample reaction volume $(0.04 \mathrm{ml})$, and $\mathrm{d}$ is the light path $(0.6 \mathrm{~cm})$. Paraoxonase activity was expressed as U/L.

PON1 genotyping: Genomic DNA was extracted from EDTA-anticoagulant peripheral blood leucocytes using QIAamp DNA blood Mini kit supplied by Qiagen, Hilden, Germany. Genotyping was conducted by polymerase chain reaction (PCR) amplification followed by polymorphism-specific restriction enzyme digestion by AlwI (Fermentas international Inc, Hurrington Court, Burlington Ontario, Canada), and gel electrophoresis analysis. The Q192R polymorphisms $(\mathrm{A} / \mathrm{G})$ were determined following a protocol developed by Adkins et al. (1993) ${ }^{18}$. The sense primer 5'-TAT TGT TGC TGT GGG ACC TGA G-3' and anti-sense primer 5'-CAC GCT AAA CCC AAA TAC ATC TC-3' which encompass the 192 polymorphic region of the human PON1 gene (CCA/CGA) were used. These primers were designed by metabion-international, AG, Germany. PCR was carried out in $50 \mu \mathrm{l}$ final volume containing $100 \mathrm{ng}$ genomic DNA, $25 \mathrm{pmol}$ of each primer, $0.2 \mathrm{mM}$ of 
each dNTPs, $50 \mathrm{mM} \mathrm{KCl}, 20 \mathrm{mM}$ Tris- $\mathrm{HCl}(\mathrm{pH} 8)$, $1.5 \mathrm{mM} \mathrm{Mg} \mathrm{Cl} 2$ and $2.5 \mathrm{U}$ of Taq DNA polymerase (Promega, USA). After denaturing the DNA for $5 \mathrm{~min}$ at $95^{\circ} \mathrm{C}$, the reaction mixture was subjected to 46 cycles of denaturation for $1 \mathrm{~min}$ at $94^{\circ} \mathrm{C}, 30 \mathrm{~s}$ annealing at $61^{\circ} \mathrm{C}$ and $1 \mathrm{~min}$ extension at $72^{\circ} \mathrm{C}$ using Hybaid thermal cycler. All PCR products were electrophoresed on $2 \%$ agarose gel stained with ethidium bromide and visualized by UV transillumination. The 99 bp PCR products were digested with $8 \mathrm{U}$ AlwI restriction endonuclease overnight at $50^{\circ} \mathrm{C}$. The digested products were separated on $4 \%$ agarose gel with ethidium bromide staining and ultraviolet transillumination. The RRgenotype (arginine) contains a unique AlwI restriction site which results in 65 and 34 bp products and the QQ-genotype (glutamine) will not cut which results in a single band at $99 \mathrm{bp}$, whereas, the heterozygous QRgenotype appear as 3 bands at 99, 65, and $34 \mathrm{bp}$.

Measurement of intima-media thickness (IMT): In order to estimate early-stage atherosclerosis ultrasonographic scanning of the carotid artery was performed using an echographic system (ATL HDI 5000, USA) with an electric linear transducer (midfrequency $7.5 \mathrm{MHz}$ ). The detection limit of this echosystem using $7.5 \mathrm{MHz}$ was $0.1 \mathrm{~mm}$. Scanning of the extracranial common carotid artery, the carotid bulb, and the internal carotid artery (ICA) in the neck was performed bilaterally from two different longitudinal scanning (i.e. anterolateral and posterolateral) as well as cross-sectional scanning. Characteristic patterns showed two parallel echogenic lines separated by a hypoechogenic space. The IMT was defined as the distance from the leading edge of the first echogenic line to the leading edge of the second line. The first line represented luminal-intimal transition and the second one medial-adventitial transition. The site of the greatest thickness including a plaque lesion was sought along the arterial walls. Three determinations of IMT were conducted at the site of the thickest point and two adjacent points (located $1 \mathrm{~cm}$ upstream and $1 \mathrm{~cm}$ downstream from the thickest point). These three determinations were averaged (mean IMT).

\section{Statistical Analysis}

Statistical Package for Social Science (SPSS) program version 15 was used for analysis of data. Data was summarized as mean \pm SD. Mann-Whitney test was used for analysis of 2 quantitative data. Pearson's correlation was used for detection of the relation between 2 variables. P-value was considered significant if $<0.05$.

\section{RESULTS}

The main demographic and biochemical features (mean $\pm \mathrm{SD}$ ) in SLE patients and control subjects are shown in Table (1). There was no significant difference between the two groups regarding age, SBP, DBP, FBG, TG and creatinine. On the other hand, patients with SLE had significantly higher mean value of BMI, TC, LDL-C ( $<<0.05$ in all) and ESR $(\mathrm{p}<0.0001)$ and a significantly lower mean value of HDL-C $(\mathrm{p}<0.05)$ compared to control subjects. There was a statistically significant lower mean value of PON1 activity in SLE patients $(525.2 \pm 198.7$ U/L) compared to control group $(702.1 \pm 214.8 \mathrm{U} / \mathrm{L})$ $(\mathrm{p}<0.0001) \quad$ (Figure 1). The mean IMT was significantly higher in SLE patients $(0.74 \pm 0.38 \mathrm{~mm})$ compared to control subjects $(0.35 \pm 0.09 \mathrm{~mm})$ $(\mathrm{p}<0.0001)$ (Figure 2).

Of the 40 SLE patients $6(15 \%)$ had IMT $\geq 1 \mathrm{~mm}$ and $34(85 \%)$ had IMT $<1 \mathrm{~mm}$. PON1 activity was significantly lower in SLE patients with IMT $\geq 1 \mathrm{~mm}$ $(440.8 \pm 95.6 \mathrm{U} / \mathrm{L})$ compared to patients with IMT $<1 \mathrm{~mm} \quad(564.8 \pm 87.96 \mathrm{U} / \mathrm{L}) \quad(\mathrm{p}<0.05)$. Also, a significant negative correlation was found between PON1 activity and the IMT $(\mathrm{p}<0.05)$ (Table 2$)$.

There was a significant negative correlation between PON1 activity and SLEDAI score $(\mathrm{P}<0.05)$. There was no significant correlation between PON1 activity and either TC, LDL-C, HDL-C or TG levels. Also, there was no correlation between PON1 activity and age, dose of corticosteroids, disease duration, SBP, DBP, BMI, ESR, FBG or creatinine level (Table 2).

The prevalence of Q192R SNP in patients and controls is shown in Table (3). Of all SLE patients 13 $(33.75 \%)$ were QQ, $20(48.75 \%)$ were QR and $7(17.5 \%)$ were RR. There was no statistically significant difference between SLE patients and the control group as regards the prevalence of either QQ, QR or RR polymorphisms.

Table (4) shows the demographic and biochemical data of SLE patients in relation to Q192R polymorphism. PON1 activity was lowest in QQ group, intermediate in $\mathrm{QR}$ group and highest in $\mathrm{RR}$ group $(\mathrm{p}=0.002)$ and the mean IMT value was highest in RR group, intermediate in $\mathrm{QR}$ group and lowest in QQ group $(\mathrm{p}<0.05)$. There was a statistically significant difference between the three groups as regards total cholesterol $(\mathrm{p}<0.05)$ and LDL-C $(\mathrm{p}<0.05)$, with the highest level being in the RR group and the lowest in the QQ group. There was no statistically significant difference as regards age, BMI, SBP, DBP, FBG, serum creatinine, triglycerides, HDL-C, ESR or SLEDAI score between the three groups. 
Nabih, et al.: Paraoxonase activity and atherosclerosis in SLE

Table 1. Demographic and biochemical characteristics in SLE patients and control subjects.

\begin{tabular}{lccc}
\hline \multicolumn{1}{c}{ Characteristic } & $\begin{array}{c}\text { SLE }(\mathbf{N}=\mathbf{4 0}) \\
\text { Mean } \pm \text { SD }\end{array}$ & $\begin{array}{c}\text { Control }(\mathbf{N}=20) \\
\text { Mean } \pm \text { SD }\end{array}$ & P-value \\
\hline Demographic features & & & 0.85 \\
Age (years) & $27.63 \pm 6.11$ & $27.8 \pm 4.61$ & $0.001^{*}$ \\
\hline Metabolic features & & & 0.13 \\
BMI (kg/m2) & $27.95 \pm 3.48$ & $24.2 \pm 1.26$ & 0.18 \\
SBP (mmHg) & $117 \pm 18.41$ & $112 \pm 10.33$ & 0.6 \\
DBP (mmHg) & $78 \pm 11.86$ & $71.5 \pm 8.18$ & $0.004^{*}$ \\
FBG (mg/dl) & $111 \pm 15.3$ & $108 \pm 11.4$ & 0.091 \\
Cholesterol (mg/dl) & $214.93 \pm 37.11$ & $183.8 \pm 14.54$ & $0.001^{*}$ \\
Triglycerides (mg/dl) & $151.83 \pm 64.52$ & $110.3 \pm 18.8$ & $0.001^{*}$ \\
HDL-C (mg/dl) & $42.73 \pm 5.04$ & $49.4 \pm 3.95$ & 0.5 \\
LDL-C (mg/dl) & $146 \pm 33.58$ & $112.4 \pm 12.7$ & $<0.0001^{*}$ \\
Creatinine (mg/dl) & $0.64 \pm 0.14$ & $0.6 \pm 0.11$ & - \\
ESR (mmHg/lst hour) & $60.36 \pm 23.74$ & $15.42 \pm 3.68$ & $<0.0001^{*}$ \\
SLEDAI & $7.36 \pm 5.99$ & - & $<0.0001^{*}$ \\
Paraoxonase activity (U/L) & $525.2 \pm 198.7$ & $702.1 \pm 214.8$ & $0.35 \pm 0.09$ \\
IMT (mm) & $0.74 \pm 0.38$ & &
\end{tabular}

$*=$ significantly different at $\mathrm{p}<0.05$

Table 2. Correlation between the studied parameters among SLE patients.

\begin{tabular}{|c|c|c|c|c|}
\hline \multirow{2}{*}{ Variables } & \multicolumn{2}{|c|}{ Paraoxonase } & \multicolumn{2}{|c|}{ IMT } \\
\hline & $\mathbf{r}$ & P-value & $\mathbf{r}$ & P-value \\
\hline \multicolumn{5}{|l|}{ Demographic features } \\
\hline Age (years) & -0.08 & 0.68 & -0.07 & 0.71 \\
\hline Disease duration (years) & -0.14 & 0.52 & -0.01 & 0.9 \\
\hline Current steroid dose (mg) & -0.13 & 0.49 & -0.19 & 0.31 \\
\hline \multicolumn{5}{|l|}{ Metabolic features } \\
\hline BMI (kg/m2) & 0.28 & 0.13 & 0.04 & 0.84 \\
\hline $\mathrm{SBP}(\mathrm{mmHg})$ & -0.24 & 0.21 & -0.22 & 0.24 \\
\hline $\mathrm{DBP}(\mathrm{mmHg})$ & -0.21 & 0.26 & -0.18 & 0.35 \\
\hline FBG (mg/dl) & 0.31 & 0.24 & 0.15 & 0.41 \\
\hline Cholesterol (mg/dl) & 0.22 & 0.25 & -0.04 & 0.85 \\
\hline Triglycerides (mg/dl) & 0.17 & 0.37 & 0.09 & 0.62 \\
\hline HDL-C (mg/dl) & -0.13 & 0.51 & -0.04 & 0.84 \\
\hline LDL-C (mg/dl) & 0.18 & 0.34 & -0.09 & 0.61 \\
\hline Creatinine (mg/dl) & 0.06 & 0.76 & 0.16 & 0.41 \\
\hline ESR (mmHg/1st hour) & -0.34 & 0.07 & 0.3 & 0.11 \\
\hline SLEDAI & -0.4 & $0.03 *$ & -0.41 & 0.06 \\
\hline Paraoxonase activity (U/L) & ---- & ---- & -0.58 & $0.001 *$ \\
\hline IMT (mm) & -0.58 & $0.001 *$ & ---- & ---- \\
\hline
\end{tabular}

* means significantly different at $\mathrm{p}<0.05$ 
Nabih, et al.: Paraoxonase activity and atherosclerosis in SLE

Table 3. Prevalence of Q192R SNP frequencies in SLE patients and controls.

\begin{tabular}{lccccc}
\hline \multirow{2}{*}{ Characteristic Q192R } & \multicolumn{2}{c}{ SLE patients } & \multicolumn{2}{c}{ Control } & \multirow{2}{*}{ P-value } \\
\cline { 2 - 5 } & Number & $(\%)$ & Number & $(\%)$ & \\
\hline QQ & 13 & $(33.75 \%)$ & 7 & $(35 \%)$ \\
QR & 20 & $(48.75 \%)$ & 9 & $(45 \%)$ & 0.9 \\
RR & 7 & $(17.5 \%)$ & 4 & $(20 \%)$ \\
\hline * significantly different at $\mathrm{p}<0.05$ & & & &
\end{tabular}

Table 4. Demographic and biochemical data of SLE patients in relation to Q192R polymorphism.

\begin{tabular}{lcccc}
\hline \multicolumn{1}{c}{ Variables } & QQ $(\mathbf{N}=\mathbf{1 3})$ & QR $(\mathbf{N}=\mathbf{2 0})$ & RR $(\mathbf{N}=\mathbf{7})$ & P-value \\
\hline Age (years) & $26.9 \pm 9.3$ & $30.4 \pm 6.2$ & $29.0 \pm 9.2$ & 0.23 \\
SBP (mmHg) & $124.3 \pm 14.4$ & $129.4 \pm 22.2$ & $130.1 \pm 16.0$ & 0.5 \\
DBP (mmHg) & $85.0 \pm 8.8$ & $87.8 \pm 11.4$ & $88.1 \pm 7.4$ & 0.17 \\
FBG (mg/dl) & $107 \pm 11.2$ & $115 \pm 11.1$ & $113 \pm 10.5$ & 0.6 \\
Total cholesterol (mg/dl) & $151.8 \pm 38.5^{\mathrm{a}}$ & $168.7 \pm 33.8^{\mathrm{b}}$ & $194.2 \pm 51.3^{\mathrm{c}}$ & $0.003^{*}$ \\
Triglycerides (mg/dl) & $155.1 \pm 46.6$ & $140.3 \pm 32.4$ & $157.6 \pm 54.3$ & 0.22 \\
HDL-C (mg/dl) & $44.0 \pm 5.4$ & $43.9 \pm 7.1$ & $42.4 \pm 7.8$ & 0.7 \\
LDL-C (mg/dl) & $112.8 \pm 29.3^{\mathrm{a}}$ & $146.5 \pm 31.7^{\mathrm{b}}$ & $174.3 \pm 40.3^{\mathrm{c}}$ & $0.002^{*}$ \\
Creatinine (mg/dl) & $0.68 \pm 0.2$ & $0.64 \pm 0.2$ & $0.71 \pm 0.3$ & 0.7 \\
ESR (mmHg/1st hour) & $61.4 \pm 20.64$ & $58 \pm 21.14$ & $68.36 \pm 13.34$ & 0.9 \\
SLEDAI & $6.53 \pm 4.11$ & $6.48 \pm 5.22$ & $7.32 \pm 5.74$ & 0.9 \\
Paraoxonase activity (U/L) & $647.8 \pm 203.4 \mathrm{a}$ & $558.2 \pm 187.0^{\mathrm{b}}$ & $434.3 \pm 150.8^{\mathrm{c}}$ & $0.002^{*}$ \\
IMT (mm) & $0.62 \pm 0.29^{\mathrm{a}}$ & $0.74 \pm 0.31^{\mathrm{b}}$ & $0.86 \pm 0.29^{\mathrm{c}}$ & $0.03^{*}$ \\
\hline Differt alphatical
\end{tabular}

Different alphabetical symbols indicate statistically significant difference

$*$ = significantly different at $\mathrm{p}<0.05$.

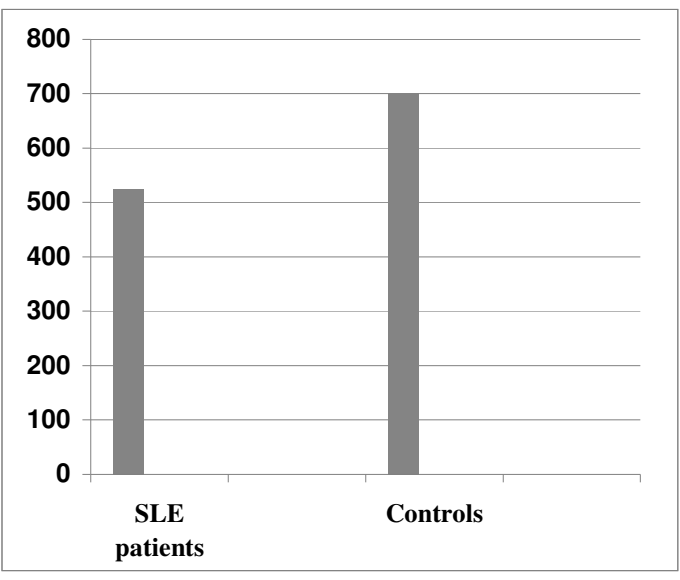

Figure 1. PON1 activity in SLE \& controls (U/L).

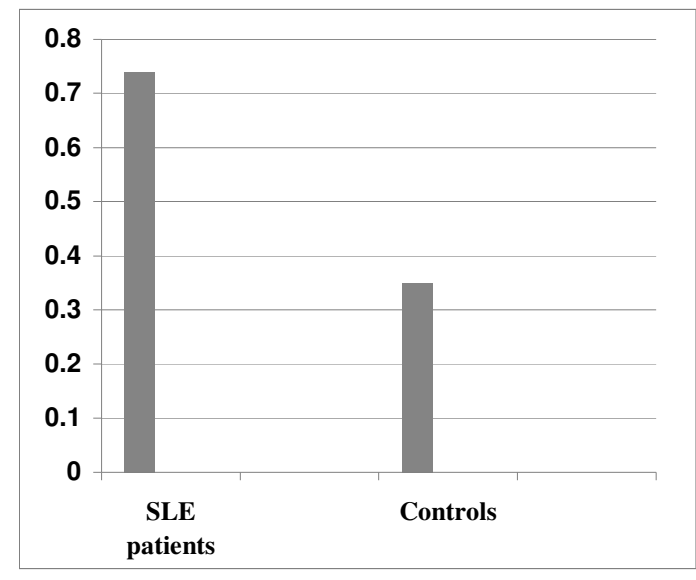

Figure 2. IMT in SLE \& controls (mm). 


\section{DIsCussion}

Patients with SLE have increased morbidity and mortality from accelerated atherosclerosis with consequent cardio- and cerebrovascular events. Clinical atherosclerotic events have been documented in $6-12 \%$ of SLE patients, while up to $40 \%$ of SLE patients are estimated to have subclinical plaque formation $^{19}$.

Excessive lipid peroxidation is a major factor for accelerated atherosclerosis observed in patients with SLE. PON1, a liver-produced glycoprotein enzyme bound to the surface of HDL, is at least partially responsible for the inhibitory effects of HDL on LDL peroxidation $^{20,22}$ and also has been demonstrated to hydrolyze oxidized lipid or lipid hydroperoxides in $\mathrm{LDL}^{7}$. Accordingly, Watson et al. reported that inactivation of PON1 reduced the ability of HDL to inhibit both the oxidation of LDL and the interaction between macrophages and endothelium ${ }^{22}$, both likely key factors in the inflammatory changes underlying atherogenesis. Finally, PON1 activity appears to play a role in maintaining the endothelial-atheroprotective effects of $\mathrm{HDL}^{23}$.

In the present study, the carotid IMT was measured as a marker of accelerated atherosclerosis in women with SLE. The mean value of IMT was significantly higher in SLE patients compared to healthy controls $(\mathrm{p}<0.0001)$.

Our study revealed a significantly lower PON1 activity in SLE patients compared to controls $(\mathrm{p}<0.0001)$. There was a significant negative correlation between PON1 activity and IMT in SLE patients $(\mathrm{p}<0.001)$. Also, Patients with IMT $\geq 1 \mathrm{~mm}$ had significantly lower PON1 activity when compared to patients with $\mathrm{IMT}<1 \mathrm{~mm}$ $(\mathrm{p}<0.05)$.These results confirm the previous observation of low PON1 activity in SLE patients with clinical atherothrombotic complications compared to those without such complications ${ }^{14,24}$, suggesting a pathogenic significance for PON1activity in the development of atherosclerosis in lupus patients. In disagreement with our results, Tripi et al. (2006) in their study, observed no significant association with carotid vascular disease in SLE patients ${ }^{25}$.

Most previous studies reported a decline in the PON1 activity in SLE patients ${ }^{24,26,27}$. These investigators assessed the PON1 activity by paraoxon as a substrate in their assay. On the other hand, Tripi et al. (2006) $)^{25}$ as well as Kiss et al. (2007) ${ }^{14}$ used both phenyl acetate and paraoxon as substrates in their assay in the same SLE patients, and both studies found a significant decline in the PON 1 activity when assessed by paraoxon. However, on assessment of the PON 1 activity by phenyl acetate, Tripi et al. (2006) reported a significant increase in the PON1 activity in their patients ${ }^{25}$, whereas, Kiss et al.,2007 did not find any significant change in the PON1 activity ${ }^{14}$. In our study we used paraoxon as a substrate for assessment of the PON 1 activity.

The mechanism of decreased PON1 activity in SLE and whether it is an association or a consequence of SLE remains unclear. Tripi et al. (2006), concluded that low PON1 activity is independently associated with $\mathrm{SLE}^{25}$. The PON1 gene is located on chromosome 7q21.3 at $94.6 \mathrm{Mb}$ which is in close proximity to a linkage peak on $7 \mathrm{q} 21.1$ at $77.5 \mathrm{Mb}$ for SLE ${ }^{28}$. Thus, PON1 is both a potential positional and a potential biologic candidate gene for SLE. On the contrary, reduced PON1 activity could be a consequence of inflammation and oxidative stress $^{26}$. Since inflammation and proinflammatory cytokines are associated with low PON1 activity, reduced PON1 activity could be due to inflammation in SLE patients $^{29,32}$. It has been speculated that not only might a chronic decrease in PON1 activity increase susceptibility to atherosclerosis but that more acute declines due to some intercurrent acute inflammatory condition could exacerbate LDL oxidation and, thus, foam cell generation in a critical part of a preexisting atheromatous lesion, predisposing it to rupture and to an acute ischemic event due to clotting on the torn surface of the lesion ${ }^{33}$.

A statistically significant negative correlation between PON1 activity and SLE disease activity assessed by SLEDAI score was observed in our study $(\mathrm{p}<0.05)$. In accordance with our finding, Batuca et al. (2009) found a significant negative correlation between PON1 activity and British Isles Lupus Assessment Group (BILAG-2004) disease activity index ${ }^{26}$. However, other studies found no correlation between PON1 activity and SLEDAI ${ }^{14,24}$.

Inhibition of PON1activity by increased oxidative stress, which has been implicated in the pathogenesis of SLE, has also been considered ${ }^{34}$. It has been reported that SLE activity is associated with deterioration of the antioxidant status ${ }^{27}$. Increased oxidative stress inactivates PON1, and a decline in the PON1 activity in turn augments oxidative stress. Therefore, the triad of disease activity, oxidative stress, and PON1 activity forms a vicious circle and this explains the negative correlation between PON1 activity and SLEDAI. ${ }^{34}$

In the present study, total cholesterol and LDL-C were significantly increased and HDL-C was significantly decreased in patients group compared to controls $(\mathrm{p}<0.05)$, but no significant difference in triglycerides levels was observed. However, there was no correlation between TC, LDL-C, HDL-C or triglycerides levels and PON1 activity. Similarly, Kiss et al. ${ }^{14}$ reported no correlation between PON1 activity and lipid parameters in SLE patients. 
The concentration and mainly the activity of PON1 can be modified by several factors. Different polymorphisms have been described in the encoding and promoter regions of the PON1 gene, which affect serum PON1 activity and concentration, and hence the extent of LDL oxidation, and the risk of CAD in nonSLE patients. ${ }^{33,35,12}$ Many studies in human populations have suggested that these polymorphisms may increase the risk for atherosclerosis. ${ }^{33}$ Nongenetic factors such as age, gender, drugs and smoking may also influence PON1 activity. ${ }^{14}$ A strong association between $P O N 1 Q 192 R$ polymorphism and PON1 activity has been found. ${ }^{36}$ One study reported that paraoxonase activity was determined $46 \%$ by PON1192 genotype, $16 \%$ PON155, and $13 \%$ by PON1 concentration. ${ }^{35}$

In the present work, both PON1 activity and PON1 Q192R polymorphism in SLE patients were studied. We investigated the effect of polymorphism on serum PON1 activity, various biochemical data and subclinical carotid vascular disease measures (IMT) in SLE patients.

There was no significant difference in the prevalence of any of the PON1 Q192R polymorphisms in SLE patients when compared to controls. Similar results were obtained by Tripi at al. $(2006)^{25}$ and Abdel-Aziz et al. $(2008)^{24}$, who found no significant association between PON1 Q192R gene polymorphism and the risk of SLE. These results indicate that the PON1 Q192R gene polymorphism is not related to genetic susceptibility to SLE. However, there was a significant association between PON1 Q192R polymorphism and PON1 activity in SLE patients. PON1 activity was highest in RR genotype, intermediate in $\mathrm{QR}$ genotype and lowest in $\mathrm{QQ}$ genotype $(\mathrm{p}=0.002)$. Our results were consistent with previous studies. ${ }^{24,25,36}$

There was a significant increase in the IMT in patients with RR genotype compared to $\mathrm{QR}$ and $\mathrm{QQ}$ genotypes and in $\mathrm{QR}$ compared to QQ $(\mathrm{p}<0.05)$. The association between PON1 192R allele genotype and CAD have been previously reported. . $^{13,24,33,36}$

HDL isolated from RR homozygotes, although most active in the hydrolysis of paraoxon, was found to be much less effective at protecting LDL against lipid peroxidation than HDL from either QQ homozygotes or QR heterozygote ${ }^{13,37}$. Aviram et al. ${ }^{37}$ and Mackness et al. ${ }^{38}$ demonstrated that purified PON1Q (low activity phenotype) was more effective than PON1 R in protection against LDL peroxidation. HDL protected LDL from oxidative modification, whatever the combination of PON1 alloenzymes present in it. However, with regard to the PON1Q192R polymorphism, PON1 QQ-HDL was most efficient at protecting LDL against oxidative modification and PON1 RR-HDL least efficient. This may explain why in some case control studies the PON1 R-allele was associated with CAD. . $^{13,24,33,38}$

PON1Q192R genotypes have been significantly associated with variation in the plasma concentration of HDL-C, LDL-C, and triglycerides. Homozygotes for the low-activity allele of PON1 had a less atherogenic lipoprotein profile than did heterozygotes and homozygotes for the high-activity allele ${ }^{39}$. In our study, there were significantly higher mean levels of $\mathrm{TC}$ and LDL-C in RR genotype compared to QR and QQ genotypes and in QR compared to QQ genotype $(\mathrm{p}<0.05)$. No significant difference was observed in triglyceride or HDL-C levels.

In conclusion, although there was no association between any of the PON1Q192R polymorphisms and SLE, PON1 activity was significantly decreased in SLE patients and was significantly correlated with the severity of atherosclerotic lesions. And thus, PON1 activity may have a significant effect on the development of cardiovascular complications in SLE patients. There are over 200 SNPs in PON1gene and so it is possible that other SNP in PON1gene may affect SLE risk. Low serum PON1 activity independent of genotype may be due to disease related acquired factors interfering with PON1 activity such as inflammatory and oxidative stress.

[Disclosure: Authors report no conflict of interest]

\section{REFERENCES}

1. Manzi S, Meilahn EN, Rairie JE, Conte CG, Medsger TA Jr, Jansen-McWilliams L, D'Agostino RB, Kuller LH: Age-specific incidence rates of myocardial infarction and angina in women with systemic lupus erythematosus: comparison with the Framingham Study. Am J Epidemiol. 1997; 145: 408-415.

2. Ward MM, Pyun E, Studenski S: Causes of death in systemic lupus erythematosus: long-term follow up of an inception cohort. Arthritis Rheum. 1995; 38: 1492-9.

3. Manzi S. Systemic lupus erythematosus: a model for atherogenesis ? Rheumatology (Oxford). 2000; 39: 353-9.

4. Sarzi-Puttini P, Atzeni F, Carrabba M: Cardiovascular risk factors in systemic lupus erythematosus and in antiphospholipid syndrome. Minerva Med. 2003; 94(2):63-70.

5. Navab M, Ananthramaiah GM, Reddy ST, Van Lenten BJ, Ansell BJ: The oxidation hypothesis of atherogenesis: the role of oxidized phospholipids and HDL. J Lipid Res. 2004; 45: 993-1007.

6. Mackness B, Durrington PN, Mackness MI: The paraoxonase gene family and coronary heart disease. Curr Opin Lipidol. 2002; 13: 357-362. 
7. Cao H, Girard-Globa A, Berthezene F, Moulin P: Paraoxonase protection of LDL against peroxidation is independent of its esterase activity towards paraoxon and is unaffected by the $\mathrm{Q} \rightarrow \mathrm{R}$ genetic polymorphism. J Lipid Res. 1999; 40: 133139.

8. Shih DM, Gu L, Xia YR, Navab M, Li WF: Mice lacking serum paraoxonase are susceptible to organophosphate toxicity and atherosclerosis. Nature. 1998;394: 284-287.

9. Shih DM, Xia YR, Wang XP, Miller E, Castellani LW: Combined serum paraoxonase knockout/apolipoprotein E knockout mice exhibit increased lipoprotein oxidation and atherosclerosis. J Biol Chem. 2000; 275: 17527-17535.

10. Mackness B, Mackness MI, Durrington PN, Evans AE: Paraoxonase activity in two healthy populations with differing rates of coronary heart disease. Eur J Clin Invest. 2000; 30: 4-10.

11. Hegele RA: Paraoxonase genes and disease. Ann Med. 1999;31: 217-224.

12. Bhattacharyya T, Nicholls S J, Topol E J, Zhang R, Yang Xia, Schmitt BA, Shao M, Brennan Danielle M, Ellis SG, Brennan ML, Allayee H, Lusis AJ, Hazen SL: Relationship of Paraoxonase 1 (PON1) Gene Polymorphisms and Functional Activity with Systemic Oxidative Stress and Cardiovascular Risk. JAMA. 2008; 299(11): 1265-1276.

13. Mackness MI, Mackness B, Durrington PN, Fogelman AM, Berliner JXLA, Navab M, Shih D \& Fonarow GC: Paraoxonase and coronary heart disease. Curr Opin Lipidol. 1998; 9: 319-324.

14. Kiss E, Seres I, Tarr T, Kocsis Z, Szegedi G, Paragh G: Reduced paraoxonase 1 activity is a risk for atherosclerosis in patients with systemic lupus erythematosus. Ann N Y Acad Sci. 2007; 1108: 8391.

15. Hochberg MC: Updating the American College of Rheumatology revised criteria for the classification of systemic lupus erythematosus [letter]. Arthritis Rheum.1997; 40: 1725.

16. Bombardier C, Gladman DD, Urowitz MB, Caron D, Chang CH: Derivation of the SLEDAI. A disease activity index for lupus patients. The Committee on Prognosis Studies in SLE. Arthritis Rheum.1992; 35: 630-640.

17. Furlong CE, Richter RJ, Seidel SL, Motulsky AG: Role of genetic polymorphism of human plasma paraoxonase/arylesterase in hydrolysis of the insecticide metabolites chlorpyrifos oxon and paraoxon. Am J Hum Genet. 1988; 43(3): 230-238.

18. Adkins $\mathrm{S}$, Gan KN, Mody $\mathrm{M}$, La Du BN: Molecular basis for the polymorphic forms of human serum paraoxonase/ arylesterase: Glutamine or arginine at position 191, for the respective A or B allozymes. Am.J.Hum.Genet. 1993; 52 (3): 598608

19. Urowitz MB, Gladman DD: Accelerated atheroma in lupus background. Lupus. 2000; 9: 161-5.
20. Mackness MI, Arrol S, Abbott C, and Durrington PN: "Protection of low-density lipoprotein against oxidative modification by high-density lipoprotein associated paraoxonase," Atherosclerosis. 1993; 104(2): 129-135.

21. Graham A, Hassall DG, Rafique S. and Owen JS: "Evidence for a paraoxonase-independent inhibition of low-density lipoprotein oxidation by high-density lipoprotein," Atherosclerosis. 1997; 135(2): 193-204.

22. Watson AD, Berliner JA, Hama SY: "Protective effect of high density lipoprotein associated paraoxonase. Inhibition of the biological activity of minimally oxidized low density lipoprotein," J Clinic Invest. 1995; 96(6): 2882-2891.

23. Besler C, Heinrich K, Rohrer L: "Mechanisms underlying adverse effects of HDL on eNOSactivating pathways in patients with coronary artery disease," J Clinic Invest. 2011;121(7): 2693-2708.

24. Abdel-Azeez HA, Sharaf SM, Emerah AA. and Shoeib SA: Paraoxonase 1 activity and genotyping in systemic lupus erythematosus and their relationships with cardiovascular complications. Egypt. J. Med. Hum. Genet. 2008; 9(2): 201-15.

25. Tripi LM, Manzi S, Chen Q, Kenney M, Shaw P, Kao A: Relationship of serum paraoxonase 1 activity and paraoxonase 1 genotype to risk of systemic Lupus erythematosus. Arthritis Rheum. 2006; 54 (6): 1928-39.

26. Batuca JR, Ames PR, Amaral M, Favas C, Isenberg DA, Delgado Alves J: Anti-atherogenic and anti-inflammatory properties of high-density lipoprotein are affected by specific antibodies in systemic lupus erythematosus. Rheumatology (Oxford). 2009; 48(1): 26-31.

27. Delgado AJ, Ames PR, Donohue S, Stanyer L, Nourooz-Zadeh J, Ravirajan C: Antibodies to highdensity lipoprotein and beta2-glycoprotein I are inversely correlated with paraoxonase activity in systemic lupus erythematosus and primary antiphospholipid syndrome. Arthritis Rheum. 2002; 46(10): 2686-2694

28. Gaffney PM, Ortmann WA, Selby SA, Shark KB, Ockenden TC, Rohlf KE: Genome screening in human systemic lupus erythematosus: results from a second Minnesota cohort and combined analyses of 187 sib-pair families. Am J Hum Genet 2000; 66: $547-56$

29. Van Lenten BJ, Wagner AC, Navab M, Fogelman AM: Oxidized phospholipids induce changes in hepatic paraoxonase and ApoJ but not monocyte chemoattractant protein-1 via interleukin-6. J Biol Chem 2001; 276: 1923-9.

30. Feingold KR, Memon RA, Grunfeld C: Paraoxonase activity in the serum and hepatic mRNA levels decrease during the acute phase response. Atherosclerosis. 1998; 139: 307-15. 
31. Kumon Y, Nakauchi $Y$, Suehiro $T$, Shiinoki T, Tanimoto $\mathrm{N}$, Inoue M: Proinflammatory cytokines but not acute phase serum amyloid $\mathrm{A}$ or C-reactive protein, downregulate paraoxonase1 (PON1) expression by HepG2 cells. Amyloid. 2002; 9: 160-4.

32. Kumon Y, Suehiro T, Ikeda Y, Hashimoto K Human paraoxonase-1 gene expression by HepG2 cells is downregulated by interleukin- $1 \beta$ and tumor necrosis factor- $\alpha$, but is upregulated by interleukin6. Life Sci. 2003; 73: 2807-15.

33. Durrington P.N., Mackness B., Mackness M.I: Paraoxonase and Atherosclerosis Arterioscler Thromb Vasc Biol. 2001; 21: 473-480.

34. Camps J, García-Heredia A, Rull A, AlonsoVillaverde C, Aragonès G, Beltrán-Debón R: PPARs in regulation of paraoxonases: control of oxidative stress and inflammation pathways. PPAR Res. 2012; 61: 6371 .

35. Mackness M and Mackness B: Paraoxonase 1 and atherosclerosis: is the gene or the protein more important? Free Radic Biol Med. 2004; 37: $1317-$ 23.

36. Mackness B, Mackness MI, Arrol S, Turkie W, Durrington PN: Effect of the molecular polymorphisms of human paraoxonase (PON1) on the rate of hydrolysis of paraoxon. Br.J.Pharmacol. 1997; 122 (2): 265-8.

37. Aviram $\mathrm{M}$ and Rosenblat $\mathrm{M}$ : Paraoxonases 1, 2, and 3 , oxidative stress and macrophage foam cell formation during atherosclerosis development. Free Radic. Biol.Med. 2004 1; 37 (9): 1304-16.

38. Mackness M, Durrington $\mathrm{P}$, Mackness $\mathrm{B}$ : Paraoxonase 1 activity, concentration and genotype in cardiovascular disease. Curr. Opin. Lipidol. 2004; 15 (4): 399-404.

39. Hegele RA, Brunt JH, Connelly PW: A polymorphism of the paraoxonase gene associated with variation in plasma lipoproteins in a genetic isolate. Arterioscler. Thromb.Vasc.Biol. 1995; 15 (1): 89-95. 